\begin{tabular}{|c|c|c|c|}
\hline BMI & $\mathbf{N}(\%)$ & SLEDAI Mean (SD) & $P$ value \\
\hline Low (reference) & $183(9.7)$ & $2.9(2.2)$ & REF \\
\hline Normal & $655(34.5)$ & $2.7(2.4)$ & 0.3107 \\
\hline Overweight & $531(28)$ & $2.5(2.1)$ & 0.0285 \\
\hline Obese & $290(15.3)$ & $2.6(2.1)$ & 0.0285 \\
\hline Severely Obese & $237(12.5)$ & $2.5(2.1)$ & 0.0587 \\
\hline
\end{tabular}

This analysis adds further support to the existence of an obesity paradox in SLE.

Funding Source(s): The Hopkins Lupus Cohort was funded by AR 69572

\section{STUDY ON SERUM DNAASE1 ACTIVITY IN PEDIATRIC ONSET SYSTEMIC LUPUS ERYTHEMATOSUS FROM A TERTIARY CARE CENTRE IN NORTH WEST INDIA}

${ }^{1}$ Nameirakpam Johnson*, ${ }^{2} \mathrm{~N}$ Ramalingeswara, ${ }^{3}$ Amit Rawat, ${ }^{4}$ Deepti Suri, ${ }^{4}$ Surjit Singh. ${ }^{1}$ Dept. of Pediatrics, Allergy- Immunology Unit, Postgraduate Institute of Medical Education and Research; ${ }^{2}$ Advanced Pediatrics Centre, Postgraduate Institute of Medical Education and Research; ${ }^{3} P G I M E R$ Chandigarh; ${ }^{4}$ Postgraduate Institute of Medical Education and Research, Chandigarh, India

\subsection{6/lupus-2019-Ism.278}

Background DNAase is an apoptotic endonuclease responsible for degradation of chromatin released by inappropriately cleared dead cells. DNAase1 activity in systemic lupus erythematosus (SLE) patients is lower than that in inactive disease in studies conducted in adult SLE patients from developed country. There is a paucity of data on DNAase1 activity in paediatric SLE from India.

Methods A cross-sectional observational study was conducted over a period of 1 year. Thirty-three consecutive children with pediatric-onset SLE were enrolled and divided into active and inactive disease activity groups based on Systemic Lupus Erythematosus Disease Activity Index (SLEDAI) score and compared the serum DNAase1 level between the two groups.

Results Out of 33 children enrolled, 13 (39.3\%) had active disease (SLEDAI score 3) and $20(60.6 \%)$ had inactive disease activity. Mean age at diagnosis was 8.5 years and 10.2 years in active and inactive groups respectively. There is female preponderance $(66.7 \%)$ in the enrolled patients. Anti nuclear antibody (ANA) was positive in $90.9 \%$ of patients. The most common pattern of ANA was diffuse pattern (48.4\%). The patients in active disease activity group presented most commonly with nephritis (53.8\%), rash (53.8\%), arthralgia (38.5\%), oral ulcer (30.8\%) and central nervous system (CNS) involvement (38.4\%) while patients in inactive disease activity group presented with nephritis (35\%), arthralgia (35\%), rash (25\%) and CNS involvement (30\%). Class III/IV lupus nephritis was present in $25 \%$ in active disease activity group while it was present in $23.1 \%$ in inactive disease activity group. Anti-double stranded DNA (anti dsDNA) was elevated in $53.8 \%$ in active group and $50 \%$ in inactive group. Antiphospholipid antibody was present in $3(23.1 \%)$ in active disease activity group and $5(25 \%)$ in inactive disease activity group. The mean serum concentrations of DNAase1 were $15.394 \mathrm{ng} /$ $\mathrm{ml}$ in active disease group and $15.205 \mathrm{ng} / \mathrm{ml}$ in inactive disease group. There was no statistically significant difference in the serum DNAase1 concentrations between the two groups $(p=0.943)$. There was also no significant difference in the mean serum concentration of DNAase1 in patients with or without nephritis $(p=0.080)$.

Conclusions The present study could not established any correlation between serum DNAase1 levels and disease activity in pediatric-onset SLE. There was no association between serum DNAase1 levels and organ involvement such as nephritis in the enrolled patients.

Funding Source(s): None

\section{SEXUAL DYSFUNCTION IN A BRAZILIAN COHORT OF BELIMUMAB TREATED SLE PATIENTS}

Morton Scheinberg*, Andrea Pimentel Fonseca Golmia, Ricardo Golmia, Gislene Ferrarezi, Aline Pinheiro dos Santos Cortada. Clinical Research Center Hospital AACD

\subsection{6/lupus-2019-Ism.279}

Background Systematic review and metaanalysis results of sexual dysfunction in patients with systemic lúpus erythematosus are contradictory. We investigate the quality of sexual activity in 74 patients with SLE receiving standard care of therapy and the addition of monthly injections of belimumab.

Methods The Female Sexual Function Index (FSfi), obtained by applying a 19-item questionnaire that assesses six domains (sexual desire, arousal, vaginal lubrication, orgasm, sexual satisfaction and pain), was used. 